\title{
Assessing the Susceptibility of Olive Cultivars to Anthracnose Caused by Colletotrichum acutatum
}

\author{
J. Moral and A. Trapero, Departamento de Agronomía, ETSIAM, Universidad de Córdoba, Campus de Rabanales, \\ 14071 Córdoba, Spain
}

\begin{abstract}
Moral, J., and Trapero, A. 2009. Assessing the susceptibility of olive cultivars to anthracnose caused by Colletotrichum acutatum. Plant Dis. 93:1028-1036.

Selected olive (Olea europaea) cultivars were tested in the field and laboratory for their relative susceptibility to anthracnose caused by Colletotrichum acutatum. A rating scale to assess fruitrot incidence in naturally infected trees was validated by comparing ratings with direct counts of affected fruit. Fruit-rot incidence varied greatly among 20 cultivars and was correlated with the severity of branch dieback symptoms that developed after fruit-rot epidemics. For determining whether artificial inoculation can be used to predict anthracnose susceptibility in the orchard, detached fruit of 12 cultivars were inoculated with $C$. acutatum and fruit-rot severity was assessed periodically. Progress of disease severity over time fit the logistic function for all cultivars. The best correlation between fruit-rot incidence in the field and disease severity on inoculated fruit was obtained using a disease susceptibility index that integrated the maximum disease progress rate and the estimated time to reach $50 \%$ disease severity. Based on field observations and laboratory data on susceptibility to anthracnose, 21 cultivars were classified into three groups: highly susceptible (Cornicabra, Hojiblanca, Lechín de Sevilla, Manzanilla de Sevilla, Morona, Ocal, Picudo, and Verdial de Huévar); moderately susceptible (Arbequina, Arbosana, Morrut, Pajarero, and Villalonga); and resistant (Blanqueta, Empeltre, Frantoio, Koroneiki, Leccino, Morona-D, Picual, and Razzola). The assessment method may be useful to screen olive cultivars for anthracnose resistance.
\end{abstract}

Olive (Olea europaea L.) is the most extensively cultivated fruit crop in the world (10), and its great intraspecific diversity is the key to its good adaptation to the many different areas with a Mediterranean climate. Although olives are grown worldwide, the Mediterranean basin is the major cultivation area, comprising about $98 \%$ of olive trees and more than 1,200 cultivars (3). About $25 \%$ of all olive trees are grown in Spain, where the number of wellidentified cultivars is 272 (27). The Spanish olive industry presently has over 2.5 million ha with an annual olive oil production value exceeding 2.8 billion euros in the last 4 years (16). More than $65 \%$ of Spanish olive production is concentrated in the Andalusian region of southern Spain, where olive trees are an essential element of the landscape and form a mosaic of cultivars (27).

Anthracnose of olive, caused by the fungi Colletotrichum acutatum J.H. Simmonds ex Simmonds and C. gloeosporioides (Penz.) Penz. \& Sacc., is the most destructive disease of olive fruit and

Corresponding author: A. Trapero

E-mail: trapero@uco.es

Accepted for publication 18 June 2009.

doi:10.1094/PDIS-93-10-1028

(C) 2009 The American Phytopathological Society is widely distributed in many olivegrowing regions of the world $(8,13,29)$. In Spain, the disease is named for its characteristic fruit-rot and mummification syndrome, with abundant production of conidia in a gelatinous matrix ("aceituna jabonosa" or "soapy fruit") under wet conditions $(8,18)$. In recent epidemics in southern Spain, affected trees showed wilting of leaves and dieback of shoots and branches, as well as the characteristic fruitrot syndrome $(2,32)$. All isolates of Colletotrichum causing olive anthracnose in these epidemics in Andalusia were identified as $C$. acutatum $(21,25)$. However, $C$. gloeosporioides has also been identified as causal agent of olive anthracnose in Spain (2,25).

The incidence of anthracnose depends greatly on cultivar susceptibility and weather. In Andalusia, severe anthracnose epidemics only occur under favorable weather conditions in areas where susceptible cultivars are grown, such as in southern Córdoba, northern Málaga-Sevilla, and western Granada provinces. The dominant cultivars in these areas are Hojiblanca and Picudo, which are highly susceptible to anthracnose (2). A similar situation occurs in wet regions of Portugal, where the susceptible cultivar Galega vulgar is grown (29). Fortunately, the most important cultivar in Andalusia, Picual, is considered resistant to anthracnose under field conditions, although a moderate level of disease occurs when Picual trees are grown mixed with susceptible cultivars (32).

Information on the susceptibility or resistance to anthracnose in olive cultivars is based on field observations and farmer experience rather than on systematic studies. To characterize resistance levels, researchers have artificially inoculated fruit or plants only in a few cases and with variable results $(12,18)$. A related problem is that olive cultivars are frequently misidentified in the field (2). For these reasons, discrepancies in resistance or susceptibility to anthracnose for some olive cultivars are quite common $(20,21)$. An example of these discrepancies is the database of olive germplasm (3), which includes two cultivars each with two different levels of susceptibility to anthracnose. Another source of confusion is the similarity of anthracnose fruit-rot symptoms to those caused by other fungal pathogens, such as species of Alternaria, Botryosphaeria, Fusarium, and Phlyctema $(2,9,11,22)$.

The need to determine the relative susceptibility of olive cultivars to anthracnose became more evident after the establishment of the Olive World Germplasm Bank (OWGB) and the beginning of an olive breeding program in Córdoba, southern Spain $(6,27)$. The demand to assess a great number of olive cultivars and genotypes and the lack of a suitable method for their evaluation led to the development of an inoculation method to quantify resistance to Colletotrichum spp. (21) and the present work. The objectives of this study were the following: (i) to develop a method to assess the susceptibility of a large number of olive cultivars and genotypes to anthracnose caused by Colletotrichum spp. and (ii) to evaluate the relative susceptibility of selected cultivars. A preliminary report of this study has been published (24).

\section{MATERIALS AND METHODS}

Orchards. Three experimental orchards of different olive cultivars were selected; two were located in Córdoba and one in Jaén, Andalusian provinces in southern Spain. The three orchards belong to the Andalusian Institute for Research and Formation in Agriculture and Fishery (IFAPA in Spanish). The first orchard (Alameda del Obispo) was selected as a part of the Olive World Germplasm Bank (OWGB), which is located at the IFAPA Centre of Córdoba. The OWGB was planted in several stages starting in 1982, 
and by 2005 it contained 406 cultivars (6). For this study, 20 cultivars previously recorded as ranging from high to low susceptibility to anthracnose and from 10 to 25 years old were selected in the first orchard. There were four replicated trees per cultivar in a completely randomized design. The second orchard (La Mina) was an experimental site located at the IFAPA Centre of Cabra in Córdoba Province. Trees were planted in 1987, and there were 12 olive cultivars replicated 12 times in a complete block design, with one tree of each cultivar per block. The third orchard (Venta del Llano) was part of an experimental collection of olive cultivars located at the IFAPA Centre of Mengíbar in Jaén Province. Trees were planted in 1987, and replicate trees per cultivar in a completely randomized design.

Experimental orchards were managed according to the principles of commercial olive orchards in Andalusia (2,7). Each tree was planted in a $7 \times 7 \mathrm{~m}$ square, with one trunk per tree, and was pruned every 3 years beginning 5 years after planting. Several copper-based treatments (bordeaux mixture, Caldo Bordelés Vallés, IQV, 6 kg $\mathrm{Cu} / \mathrm{ha}$ ) were applied during the spring and autumn to control fungal foliar and fruit diseases caused by Fusicladium oleagineum, Pseudocercospora cladosporioides, and Colletotrichum spp. (2,7).

Assessment of disease incidence in the field. The incidence of anthracnose was assessed in each olive tree by estimating the percentage of affected fruit using a 0 to 10 rating scale. In each tree, the assessor circled the canopy looking for affected fruit in a 1- to 2-m band above the ground. The area checked was approximately $1 / 8$ $(12.5 \%)$ of the total canopy. The assessment took about 1 to 2 min, depending on there were 19 cultivars, with at least two

the total number of fruit per tree. The estimate of this number varied between 4,000 and 20,000 fruit, so observed fruit per tree varied between 500 and 2,500. Trees with a heavy fruit load had smallsized fruit that ripened slowly, making it more difficult to assess anthracnose incidence. In general, fruit were assessed while still attached to the tree, but in some cases the assessment included fallen fruit on the soil surface.

A scale that is a linear function of the logistic equation $\ln [Y /(1-Y)]$ was used. The scale was determined from the following formula:

$$
Y=\frac{1}{1+n^{(7-X)}}
$$

where $Y$ is the proportion of affected fruit, $X$ is the rating scale value, and $n$ is a constant. The scale value of 7 corresponds to the proportion $Y=0.5$ or $50 \%$ of affected fruit. This is the inflection point of the logistic curve. This value and the constant $n$ value are arbitrary, and they were selected by taking into account the initial value of proportion of affected fruit $\left(Y_{1}\right)$ and its interval:

$$
Y_{1}=\frac{1}{1+3^{(7-1)}}=\frac{1}{730}=0.14 \%
$$

Because the mean number of observed fruit per tree varied between 500 and 2,500 , the rating scale 1 and its interval included a mean incidence of one affected fruit per tree, which varied from $0.04 \%$ to $0.20 \%(1 / 2,500$ to $1 / 500)$. Mean values of $Y$ and their intervals for each rating scale value are indicated in Figure 1 and Table 1. Extreme values of the rating scale corresponded to $Y_{0}<0.04 \%$ and $Y_{10}>94 \%$. Besides the entire rating scale values from 0 to 10 , intermediate values $(0.5)$ also were

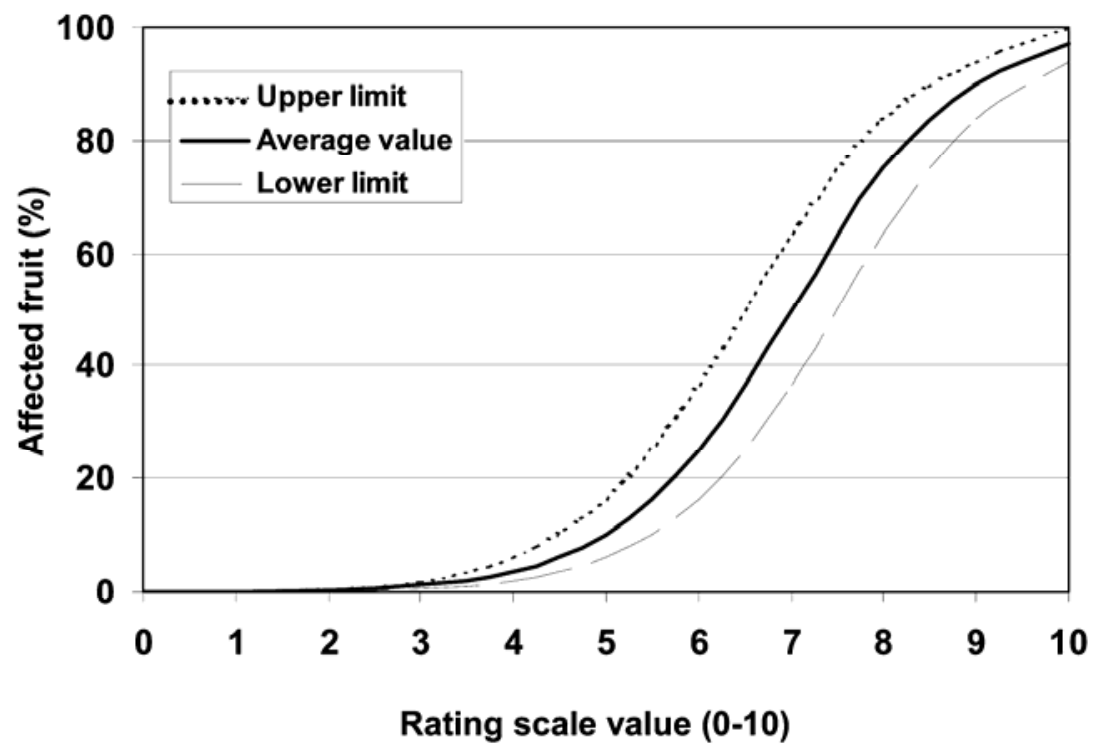

Fig. 1. Relationship between percentages of olive fruit affected by anthracnose $(Y)$ and rating scale values $(X, 0$ to 10$)$. Curves were generated by the logistic function $Y=100 /\left[1+3^{(7-X)}\right]$. Dotted lines represent the interval in the percentage of affected fruit for each scale value (see Table 1). used when there was some doubt between two consecutive scale values. To facilitate the use of the scale in the field, the three lower rating scale values were described as follows: $0=$ no affected fruit per tree, $1=$ one to three affected fruit per tree, $2=$ one to three affected fruit per each quadrant of the tree canopy. Numbers one to three of affected fruit depended mainly on the tree yield. Whereas ratings of 0,1 , or 2 depended on the number of affected fruit per tree, higher rating values were obtained by estimating directly the percentage of affected fruit in each tree (Table 1).

The relationship between the proportion of affected fruit $(Y)$ and rating scale values $(X)$ also can be expressed as:

$$
Y=\frac{1}{1+3^{(7-X)}}=\frac{1}{1+e^{-\ln 3(X-7)}}=\frac{1}{1+e^{-a X+b}}
$$

which is the regular equation for the logistic model, making $a=\ln (3)=1.099$ and $b$ $=7 \times \ln (3)=7.69$ for this particular case. This relationship also can be rewritten using the logit transformation:

$\left[\operatorname{logit}(Y)=\ln \frac{Y}{1-Y}=a X-b=\ln 3 \times(X-7)\right]$

This equation shows that scale values are a linear function of the logit of proportion of affected fruit.

To validate the 0 to 10 rating scale in the field, we selected 55 affected trees, five trees per each scale value, from different cultivars in the three experimental orchards. After they were assessed using the rating scale, trees were harvested and 2,500 fruit from each tree were selected arbitrarily and evaluated for unequivocal symptoms of anthracnose.

Disease incidence on selected cultivars in the experimental orchards. Twenty olive cultivars were selected in the three experimental orchards to assess the incidence of fruit rot using the 0 to 10 rating

Table 1. Rating scale values and average and interval of percentage of olive fruit affected by anthracnose

\begin{tabular}{lcc}
\hline $\begin{array}{l}\text { Scale value } \\
(\mathbf{0 - 1 0 )}\end{array}$ & $\begin{array}{c}\text { Affected } \\
\text { fruit }(\boldsymbol{\%})^{\mathbf{y}}\end{array}$ & $\begin{array}{c}\text { Interval } \\
(\boldsymbol{\%})^{\mathbf{y}, \mathbf{z}}\end{array}$ \\
\hline 0 & $<0.04$ & $<0.04$ \\
1 & 0.14 & $0.04 *_{-}-0.23$ \\
2 & 0.41 & $0.24-0.70$ \\
3 & 1.22 & $0.71-2.09$ \\
4 & 3.57 & $2.10-6.02$ \\
5 & 10 & $6.03-16.13$ \\
6 & 25 & $16.14-36.60$ \\
7 & 50 & $36.61-63.39$ \\
8 & 75 & $63.40-83.86$ \\
9 & 90 & $83.87-93.97$ \\
10 & 97 & $93.98-100$ \\
\hline
\end{tabular}

y Values taken from the logistic function $Y=$ $100 /\left[1+3^{(7-X)}\right]$ in which $Y=$ percentage of affected fruit and $X=$ scale value.

$\mathrm{z} *=$ Detection limit of visual assessments in the field (one affected fruit from 2,500 observed fruit per tree). 
scale (Table 2). All cultivars are considered native to Spain except Frantoio and Razzola, which are native to Italy, and Koroneiki, which is native to Greece (1). Disease incidence was assessed at different times, when most fruit of each cultivar had become black or had the value 4 in the 0 to 4 rating scale for olive fruit ripening (27). Disease incidence was assessed from the end of November to the end of January in 1997-1998, 2005-2006, and 2006-2007. There were severe epidemics of olive anthracnose in the experimental orchards during these years.

In the La Mina orchard, the severity of branch dieback was evaluated at the end of
March 2007, after 2 years of fruit-rot epidemics. Disease severity was assessed using a 0 to 5 rating scale based on the percentage of tree canopy affected: $0<$ $10 \%, 1=10$ to $25 \%, 2=25$ to $50 \%, 3=50$ to $75 \%, 4=75$ to $90 \%, 5>90 \%$. The presence of Colletotrichum spp. in affected branches was evaluated by culturing small tissue pieces from leaves, shoots, and branches on acidified potato dextrose agar (PDA) plus $100 \mathrm{mg}$ of copper sulfate $\left(\mathrm{CuSO}_{4} \cdot 5 \mathrm{H}_{2} \mathrm{O}\right)$ per liter of medium following the method of Moral et al. (23).

Inoculation of detached fruit. Olive fruit of 11 cultivars (Table 3) were collected at the onset of ripening from healthy trees in orchards located in Córdoba and Jaén provinces in 2006-2007. The fruit were green-yellow and with a value of 1 on the 0 to 4 ripening scale (27) except for fruit from cv. Picual. Two samples of Picual differing in fruit ripeness were used: Picual-G had green-yellow fruit (ripening stage 1) and Picual-M had violet fruit (ripening stage 3 ). The cultivar initially identified as Morona was later considered to be different from cv. Morona grown at OWGB of Córdoba based on morphological characters, and now it is being identified by molecular analysis (D. Barranco, University of Cordoba, Spain, personal communication). For this rea-

Table 2. Incidence of anthracnose in selected olive cultivars in three experimental orchards during 1997-1998, 2005-2006, and 2006-2007

\begin{tabular}{|c|c|c|c|c|c|c|c|c|}
\hline \multirow[b]{2}{*}{ Cultivar } & \multirow[b]{2}{*}{ Ripeness $^{\mathbf{y}}$} & \multicolumn{3}{|c|}{ Alameda del Obispo ${ }^{x}$} & \multicolumn{2}{|c|}{ La Mina $^{x}$} & \multirow{2}{*}{$\frac{\text { Venta del Llano }^{x}}{2006-07}$} & \multirow[b]{2}{*}{ Average } \\
\hline & & 1997-98 & $2005-06$ & 2006-07 & $2005-06$ & 2006-07 & & \\
\hline Arbequina & Medium & $2.0 \mathrm{de}^{\mathrm{z}}$ & $4.0 \mathrm{cde}^{\mathrm{z}}$ & $3.9 \mathrm{~d}^{\mathrm{z}}$ & $0.2 \mathrm{~d}^{\mathrm{z}}$ & $2.7 c^{z}$ & $0.3 \mathrm{c}^{\mathrm{z}}$ & 2.1 \\
\hline Arbosana & Medium & $0.0 \mathrm{e}$ & $1.0 \mathrm{fg}$ & $3.3 \mathrm{de}$ & - & - & - & 1.4 \\
\hline Blanqueta & Medium & $1.5 \mathrm{de}$ & $1.0 \mathrm{fg}$ & $2.0 \mathrm{ef}$ & $0.0 \mathrm{~d}$ & $2.0 \mathrm{c}$ & $0.0 \mathrm{c}$ & 1.1 \\
\hline Cornicabra & Late & $9.0 \mathrm{ab}$ & $7.0 \mathrm{ab}$ & $9.0 \mathrm{a}$ & - & - & $1.0 \mathrm{c}$ & 6.5 \\
\hline Empeltre & Early & $0.5 \mathrm{de}$ & $0.0 \mathrm{~g}$ & $1.3 \mathrm{fg}$ & - & - & $0.0 \mathrm{c}$ & 0.5 \\
\hline Frantoio & Early & $0.1 \mathrm{e}$ & $0.0 \mathrm{~g}$ & $0.1 \mathrm{~g}$ & $0.0 \mathrm{~d}$ & $0.2 \mathrm{~d}$ & $0.0 \mathrm{c}$ & 0.1 \\
\hline Hojiblanca & Late & $10.0 \mathrm{a}$ & $9.0 \mathrm{a}$ & $8.8 \mathrm{a}$ & $3.3 \mathrm{ab}$ & $7.6 \mathrm{a}$ & $4.5 \mathrm{ab}$ & 7.2 \\
\hline Koroneiki & Medium & $0.5 \mathrm{de}$ & $0.0 \mathrm{~g}$ & $1.0 \mathrm{f}$ & - & - & $0.0 \mathrm{c}$ & 0.4 \\
\hline Leccino & Early & - & - & - & $0.8 \mathrm{~cd}$ & $2.6 \mathrm{c}$ & $0.0 \mathrm{c}$ & 1.1 \\
\hline Lechín de Sevilla & Early & $8.8 \mathrm{ab}$ & $5.0 \mathrm{bcd}$ & $7.2 \mathrm{~b}$ & - & - & $4.0 \mathrm{~b}$ & 6.3 \\
\hline Manzanilla de Sevilla & Early & $9.5 \mathrm{a}$ & $6.0 \mathrm{bc}$ & $8.7 \mathrm{a}$ & - & - & $5.0 \mathrm{ab}$ & 7.3 \\
\hline Morona & Late & $9.3 \mathrm{a}$ & $5.5 \mathrm{bc}$ & $9.5 \mathrm{a}$ & - & - & $6.0 \mathrm{ab}$ & 7.6 \\
\hline Morrut & Late & $1.5 \mathrm{c}$ & $3.0 \mathrm{def}$ & $6.5 \mathrm{~b}$ & - & - & $0.0 \mathrm{c}$ & 2.8 \\
\hline Ocal & Early & $10.0 \mathrm{a}$ & $8.7 \mathrm{a}$ & $9.6 \mathrm{a}$ & $4.8 \mathrm{a}$ & $9.0 \mathrm{a}$ & $6.7 \mathrm{a}$ & 8.1 \\
\hline Pajarero & Early & - & - & $7.5 \mathrm{~b}$ & $2.2 \mathrm{bc}$ & $3.0 \mathrm{c}$ & $1.0 \mathrm{c}$ & 3.4 \\
\hline Picual & Early & $6.0 \mathrm{c}$ & $1.0 \mathrm{fg}$ & $5.0 \mathrm{~cd}$ & $0.2 \mathrm{~d}$ & $2.9 \mathrm{c}$ & $0.0 \mathrm{c}$ & 2.5 \\
\hline Picudo & Late & $9.8 \mathrm{a}$ & $8.3 \mathrm{a}$ & $9.5 \mathrm{a}$ & $4.4 \mathrm{a}$ & $7.9 \mathrm{a}$ & $4.0 \mathrm{~b}$ & 7.3 \\
\hline Razzola & Early & $0.5 \mathrm{de}$ & $0.0 \mathrm{~g}$ & $0.0 \mathrm{~g}$ & $0.0 \mathrm{~d}$ & $0.2 \mathrm{~d}$ & $0.0 \mathrm{c}$ & 0.1 \\
\hline Verdial de Huévar & Late & $7.0 \mathrm{bc}$ & $5.0 \mathrm{bcd}$ & $6.6 \mathrm{bc}$ & - & - & $0.0 \mathrm{c}$ & 4.4 \\
\hline Villalonga & Early & - & $2.0 \mathrm{efg}$ & $5.0 \mathrm{~cd}$ & $0.4 \mathrm{~d}$ & $5.2 \mathrm{~b}$ & $0.0 \mathrm{c}$ & 2.5 \\
\hline
\end{tabular}

${ }^{x}$ Experimental orchards in southern Spain.

y Ripeness time of cultivars in southern Spain $(1,27)$.

${ }^{\mathrm{z}}$ Fruit-rot incidence was estimated using a 1 to 10 rating scale in which binary data (proportion of affected fruit) are normalized by applying the logit transformation of proportion. Scale values were directly subjected to analysis of variance and mean comparison tests. Means with the same letter are not significantly different according to Tukey's HSD test at $P=0.05$.

Table 3. Disease reaction of selected olive cultivars inoculated with Colletotrichum acutatum ${ }^{\mathrm{u}}$

\begin{tabular}{|c|c|c|c|c|c|c|c|c|}
\hline Cultivar $^{v}$ & $\mathbf{T}_{\mathbf{0}} \mathbf{w}$ & $\mathbf{T}_{50}{ }^{w}$ & $T_{100}{ }^{w}$ & SAUDPC $^{x}$ & $\mathbf{E T}_{50} \mathbf{y}$ & MDPR $^{y}$ & DSIy & $\mathrm{ANCOVA}^{\mathrm{z}}$ \\
\hline Arbequina & 7.0 & 19.0 & 47.0 & $82.8 \mathrm{bc}$ & $22.0 \mathrm{fg}$ & $5.24 \mathrm{~d}$ & $0.24 \mathrm{~d}$ & $79.6 \mathrm{bc}$ \\
\hline Arbosana & 9.8 & 24.5 & 50.8 & $73.8 \mathrm{~cd}$ & $28.3 \mathrm{ef}$ & $6.12 \mathrm{~d}$ & $0.22 \mathrm{~d}$ & $42.6 \mathrm{~d}$ \\
\hline Blanqueta & 21.5 & 45.0 & 72.5 & $44.6 \mathrm{f}$ & $48.4 \mathrm{bc}$ & $4.42 \mathrm{~d}$ & $0.09 \mathrm{de}$ & $5.4 \mathrm{fg}$ \\
\hline Frantoio & 25.0 & 45.5 & 74.0 & $42.3 \mathrm{f}$ & $49.9 \mathrm{~b}$ & $6.09 \mathrm{~d}$ & $0.12 \mathrm{de}$ & $4.4 \mathrm{~g}$ \\
\hline Hojiblanca & 10.5 & 12.8 & 22.3 & $92.9 \mathrm{ab}$ & $15.4 \mathrm{gh}$ & $21.65 \mathrm{a}$ & $1.41 \mathrm{a}$ & $95.6 \mathrm{ab}$ \\
\hline Koroneiki & 15.5 & 46.0 & $>84$ & $45.4 \mathrm{ef}$ & $49.3 \mathrm{bc}$ & $2.42 \mathrm{~d}$ & $0.05 \mathrm{e}$ & $8.1 \mathrm{fg}$ \\
\hline Morona-D & 17.8 & 35.8 & 72.5 & $56.3 \mathrm{e}$ & $40.3 \mathrm{~cd}$ & $4.09 \mathrm{~d}$ & $0.10 \mathrm{de}$ & $10.3 \mathrm{f}$ \\
\hline Ocal & 5.8 & 9.5 & 26.8 & $97.1 \mathrm{a}$ & $12.4 \mathrm{~h}$ & $10.46 \mathrm{c}$ & $0.85 \mathrm{~b}$ & $98.0 \mathrm{a}$ \\
\hline Picual-G & 19.0 & 38.4 & 70.0 & $54.2 \mathrm{e}$ & $42.3 \mathrm{bc}$ & $4.06 \mathrm{~d}$ & $0.10 \mathrm{de}$ & $24.3 \mathrm{ef}$ \\
\hline Picual-V & 14.8 & 18.3 & 34.5 & $85.1 \mathrm{bc}$ & $20.6 \mathrm{fgh}$ & $14.72 b$ & $0.72 \mathrm{bc}$ & $81.6 \mathrm{bc}$ \\
\hline Picudo & 15.8 & 25.5 & 56.8 & $69.1 \mathrm{~d}$ & $31.6 \mathrm{de}$ & $5.56 \mathrm{~d}$ & $0.18 \mathrm{~d}$ & $31.7 \mathrm{de}$ \\
\hline Razzola & 50.3 & 80.5 & $>84$ & $8.0 \mathrm{~g}$ & $80.8 \mathrm{a}$ & $3.01 \mathrm{~d}$ & $0.04 \mathrm{e}$ & $0.05 \mathrm{~h}$ \\
\hline Verdial de Huévar & 15.0 & 19.8 & 35.5 & $81.3 \mathrm{bc}$ & $23.1 \mathrm{efg}$ & $12.95 \mathrm{bc}$ & $0.56 \mathrm{c}$ & $73.6 \mathrm{~cd}$ \\
\hline
\end{tabular}

u Detached fruit were sprayed with a conidial suspension $\left(10^{5}\right.$ conidia/ml $)$ and incubated in humid chambers at $23 \pm 2{ }^{\circ} \mathrm{C}$ for 84 days. There were 100 inoculated fruit per cultivar. Controls were sprayed with water and remained disease free (data not shown). For each column, means with the same letter are not significantly different according to Tukey's HSD test at $P=0.05$.

${ }^{v}$ Details of cultivars are in Table 1. Morona-D is an unknown cultivar that was initially identified as Morona. Picual-G and Picual-V are two samples of the same cultivar differing in the ripening stage of the fruit when they were inoculated: green-yellow (G) and violet (V).

${ }^{\mathrm{w}}$ Disease development times: days from inoculation to the following three values of disease intensity index $(\mathrm{DII})$ : $\mathrm{DII}>0\left(\mathrm{~T}_{0}\right)$, $\mathrm{DII}=50 \%\left(\mathrm{~T}_{50}\right)$, and $\mathrm{DII}=$ $100 \%\left(\mathrm{~T}_{100}\right)$. DII values were obtained by data interpolation.

${ }^{x}$ Standardized area under disease progress curve calculated by trapezoidal integration of DII values expressed as percentage of a maximum theoretical curve.

${ }^{y}$ Parameters derived from the logistic regression of DII over time: mean period for disease development or inflection point of the logistic curve (ET ${ }_{50}$ ), maximum disease progress rate (MDPR), and disease susceptibility index (DSI) calculated as DSI $=$ MDPR/ET 50 .

${ }^{\mathrm{z}}$ Means of DII estimated by analysis of covariance using time as a covariable. DII data were transformed by the logit function $(\ln [\mathrm{DII} /(100-\mathrm{DII})])$ for analysis. 
son, this unknown cultivar has been labeled Morona-D.

Inoculations were performed with the isolate Col-10 of C. acutatum, which is representative of the Spanish population of the pathogen causing olive anthracnose (25). Fruit were washed, disinfested, airdried, and sprayed with a conidial suspension $\left(10^{5}\right.$ conidia per $\mathrm{ml}$ or sterile water for the control) as previously reported (21). Inoculated and control fruit were incubated in moist chambers (plastic containers, $22 \times$ $16 \times 10 \mathrm{~cm}$, with $100 \% \mathrm{RH})$ at $23 \pm 2{ }^{\circ} \mathrm{C}$ under fluorescent lights (12-h photoperiod, $\left.40 \mu \mathrm{mol} \cdot \mathrm{m}^{-2} \cdot \mathrm{s}^{-1}\right)$. Disease severity was assessed every 2 to 3 days after inoculation by using a 0 to 5 rating scale where $0=$ no visible symptoms, $1=$ visible symptoms affecting less than $25 \%$ of the fruit surface, $2=25$ to $50 \%, 3=50$ to $75 \%, 4=75$ to $100 \%$, and $5=$ fruit completely rotted with abundant conidia in a gelatinous matrix (soapy fruit), or fruit with abundant whitegray mycelium on the surface (21). There were two replicates (moist chambers) per treatment and 25 fruit per replicate arranged in a completely randomized design. The experiment was repeated once, and data analyses were performed on the pooled data from the two experiments.

Statistical analysis. To validate the 1 to 10 rating scale, observed scale values $(X)$ for each tree were transformed into percentage of affected fruit $(Y)$ by using the logit transformation indicated earlier. Logit transformed values were regressed against the percentage of affected fruit obtained after counting anthracnose affected fruit in a sample of 2,500 fruit collected from each tree. Linear regression was performed considering the significance of the regression, coefficient of determination $\left(R^{2}\right)$, coefficient of determination adjusted for degrees of freedom $\left(R_{a}{ }^{2}\right)$, and pattern of residuals over logit transformed and fitted values.

Analysis of variance (ANOVA) was performed on the rating scale data of fruit-rot incidence and branch dieback severity in selected olive cultivars because these data satisfied the normality and homogeneity of variance requirements of ANOVA. Cultivar means were compared using Tukey's honestly significant difference (HSD) test at $P$ $=0.05$. The relationship between fruit-rot incidence and branch dieback severity was analyzed by the Pearson's correlation test.

Disease severity values of inoculated fruit were used to calculate a disease intensity index (DII) using the following formula:

$$
D I I=\frac{\sum n_{i} \times i}{5 \times N} \times 100
$$

where $i$ represents severity ( 0 to 5 ), $n_{i}$ is the number of fruit with the severity of $i$, and $N$ is the total number of evaluated fruit. For each cultivar and replication, the standardized area under the disease progress curve (SAUDPC) was calculated by trapezoidal integration of DII values over time expressed as a percent- age of a maximum theoretical curve. The SAUDPCs were transformed to $\arcsin \sqrt{S A U D P C / 100}$ when necessary for homogeneity of variance. ANOVA was performed on the SAUDPC data, and treatment means were compared using Tukey's HSD test at $P=0.05$. Curves of DII over time were adjusted to the logistic model. For each adjusted curve, two representative parameters were calculated: time in days from inoculation to the inflection point, and the slope of the curve at this point. The first parameter represents the estimated time (ET) necessary to reach $50 \%$ DII $\left(\mathrm{ET}_{50}\right)$, and the second parameter is the maximum disease progress rate (MDPR). Means of $\mathrm{ET}_{50}$ and MDPR were compared using Tukey's HSD test at $P=$ 0.05 . Data from all experiments were analyzed using Statistix 8 (Analytical Software, Tallahassee, FL).

\section{RESULTS}

Validation of the rating scale. The observed incidence of olive fruit affected by anthracnose (based on a sample of 2,500 harvested fruit per tree) and the predicted incidence (based on the logistic curve and the rating scale values previously estimated in the same trees) were similar (Fig. 2A). Linear regression of observed values expressed as percentages of affected fruit over the predicted values derived from the logistic transformation of the rating scale values was highly significant $(P<0.0001)$, with $R^{2}=0.9877, R_{a}^{2}=0.9875$, and the pattern of residuals over logit transformed and fitted values was random (Fig. 2B).

Susceptibility of cultivars in the field. Incidence of fruit rot on selected cultivars in the field varied greatly among orchards and years (Table 2). The most severe anthracnose epidemic occurred in the Ala-
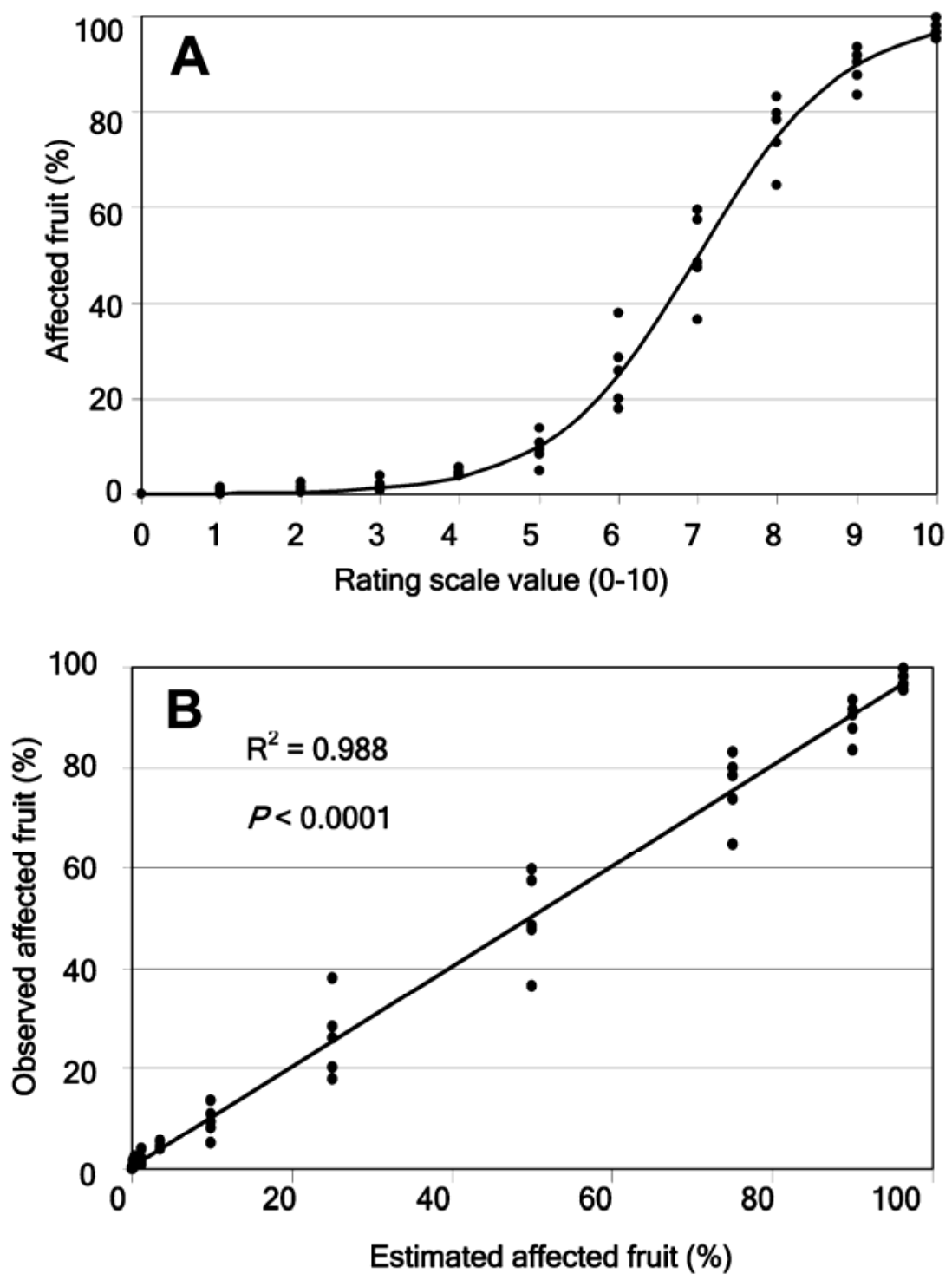

Fig. 2. Relationship between the observed (counts) and the estimated (logistic transformation) values of the percentage of fruit affected by anthracnose. A, Percentage of affected fruit observed by counts over rating scale values. Line represents the logistic function $Y=100 /\left[1+3^{(7-X)}\right]$ relating rating scale values $(X)$ with percentage of affected fruit $(Y)$. B, Linear regression of percentage of affected fruit observed by counts over percentage estimated by the logistic function. A total of 55 trees, five per each scale value, were assessed by counting the affected fruit in an arbitrary sample of 2,500 fruit per tree. 
meda del Obispo orchard in 1997-1998, whereas the lowest levels of disease occurred in the Venta del Llano orchard in 2006-2007. Trees in the latter orchard were only evaluated in 2006-2007 because of the generally low level of infection in other years. Similarly, trees in the La Mina orchard were not evaluated in 1997-1998 because they had a low level of infection. Cultivar reaction ranged continuously from highly susceptible to highly resistant. The most susceptible cultivar in all orchards was Ocal; other highly susceptible cultivars were Picudo, Hojiblanca, Manzanilla de Sevilla, Morona, Lechín de Sevilla, and Cornicabra. The most resistant cultivars were Razzola and Frantoio; other cultivars with a low level of susceptibility were reactions of the remaining cultivars were less consistent among orchards and years, although there were significant differences among them (Table 2).

The severity of branch dieback symptoms was assessed only in the La Mina orchard because it was the only orchard with an appropriate number of replications (12) for this evaluation. Branch dieback symptoms were severe $(>75 \%$ of the tree canopy affected) on cultivars highly susceptible to fruit rot (Ocal, Picudo, and Hojiblanca) but much less severe $(<10 \%$ of the tree canopy affected) on cultivars less susceptible to fruit rot (Razzola, Frantoio, and Leccino). Branch dieback severity varied significantly among cultivars and was highly correlated $(r=0.846, P<$ $0.0001)$ with the average fruit-rot incidence for each cultivar (Fig. 3). The pathogen $C$. acutatum was isolated from $<3 \%$ of the sampled leaves, shoots, and branches with dieback symptoms.

Susceptibility of cultivars in artificial inoculation. All cultivars developed fruitrot anthracnose symptoms by the end of the experiment, 84 days after inoculation. Disease incidence and severity varied Koroneiki, Leccino, and Empeltre. The

greatly with cultivar and time. The time of appearance for the first symptom varied from 5 days after inoculation in the most susceptible cultivar (Ocal) to 45 days in the most resistant (Razzola). Complete fruit rot required as little as 21 days (Hojiblanca and Ocal) to more than 84 days (Razzola and Koroneiki). Many fruit of the latter cultivars did not show symptoms at the end of the experiment. For each cultivar, three disease development times were calculated by interpolation: $\mathrm{T}_{0}=$ days from inoculation until the first fruit with symptoms appeared, $\mathrm{T}_{50}=$ days from inoculation until $50 \%$ of the fruit were affected, and $\mathrm{T}_{100}=$ days from inoculation until $100 \%$ of the fruit were affected (Table 3 ). The SAUDPC analysis separated the cultivars into seven groups, although there was overlap among cultivars (Table 3). Disease progress curves of DII for each cultivar were well described by the logistic model (Fig. 4). The two representative parameters of these curves, $\mathrm{ET}_{50}$ and MDPR, determined several susceptibility groups of cultivars (Table 3), although these groups differed according to the parameter used for comparison. For this reason, a new parameter (disease susceptibility index, DSI) was defined to integrate both parameters. DSI was calculated as:

$$
\mathrm{DSI}=\frac{\mathrm{MDPR}}{\mathrm{ET}_{50}}
$$

and it shows that cultivar susceptibility is directly proportional to the maximum disease progress rate and inversely proportional to the time to reach $50 \%$ of DII. Means of DSI were used to classify cultivars into five susceptibility groups (Table 3). Because DII data fit a logistic function well, there was a linear relationship between logit transformed values of DII and time. Therefore, an alternative data analysis was the covariance of transformed data with the logit function $(\ln [D I I /(100-D I I)])$ using cultivars as a categorical variable and time

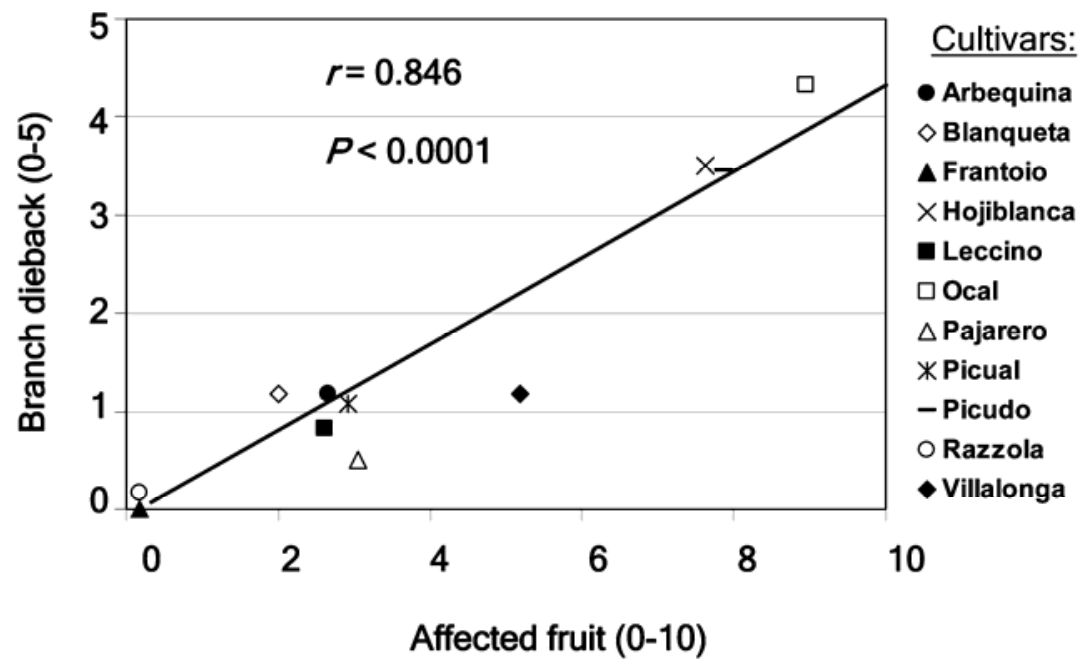

Fig. 3. Linear correlation between incidence of fruit rot and severity of branch dieback symptoms in 11 olive cultivars grown in the La Mina orchard. Symbols represent the mean of 12 repetitions of each cultivar. as a covariable. Comparison of DII means estimated by covariance analysis established eight groups of cultivars based on susceptibility (Table 3).

The two samples of cv. Picual significantly differed in susceptibility. Picual-G (ripening stage 1) had a low level of disease, whereas Picual-V (ripening stage 3) was severely affected.

Comparison between cultivar response in the field and after artificial inoculation. For 12 cultivars, susceptibility based on artificial inoculation and susceptibility based on field observations were compared by correlating each variable measured in the artificial inoculation with the average disease incidence observed in the orchard (Table 3). The correlation coefficients for the different variables were low, and some were not significant (Table 4). The lack of correlation was mainly due to discrepancies in two cultivars: Morona and Picudo. The correlation substantially increased when both these cultivars were eliminated from the analysis. Without these two cultivars, the best linear correlation was obtained with the variable DSI (Table 4). The correlation between the variable DSI and the average of anthracnose incidence in the remaining 10 cultivars, after elimination of Morona and Picudo, is illustrated in Figure 5.

The analysis of variance of DSI and the other measures of anthracnose susceptibility, together with the relationship between these variables and field observations and the need to compare our results with published data, led us to place the cultivars into three broad categories: highly susceptible, moderately susceptible, and resistant. Using these categories, the 21 cultivars evaluated in this study should be classified as follows: highly susceptible (Cornicabra, Hojiblanca, Lechín de Sevilla, Manzanilla de Sevilla, Morona, Ocal, Picudo, and Verdial de Huévar), moderately susceptible (Arbequina, Arbosana, Morrut, Pajarero, and Villalonga), and resistant (Blanqueta, Empeltre, Frantoio, Koroneiki, Leccino, Morona-D, Picual, and Razzola).

\section{DISCUSSION}

Variability of olive cultivars is being studied in 102 collections from 54 countries including 5,356 accessions (3). In part because there are so many cultivars and many poorly identified cultivars, information on susceptibility or resistance to major diseases is limited, particularly in the case of olive anthracnose (2). Until the present study, little or no information was available on methods to assess cultivars for their susceptibility to anthracnose under field and controlled conditions.

A parameter useful for assessing disease susceptibility under field conditions is disease incidence, which is calculated by counting the number of diseased fruit in a sample of detached fruit and expressing the count as the proportion or percentage 
of total fruit. Assessing disease incidence is relatively straightforward, but it becomes more difficult when the number of experimental units (trees) or observations is large. In this case, it is necessary to use other assessment methods, such as a rating scale to estimate the incidence of affected fruit (17). The rating scale developed is a useful and rapid method to estimate the incidence of affected fruit in a tree. Based on the binary nature of data and the logistic growth of the epidemics, the transformed scale data are normally distributed so they can be directly subjected to analysis of variance and other parametric analyses. This rating scale is close to the Horsfall-Barratt scale (17), but it differed from that scale because it was adjusted to the logistic function.
The rating scale was validated in the field using olive trees of several cultivars with a disease incidence from 0 to $100 \%$. The highly significant correlation indicates a good agreement (accuracy) between estimated data (rating scale) and true values (direct counts). Therefore, we conclude that scale values are useful to assess disease incidence in different cultivars with different levels of disease. The main advantage of using a disease incidence scale was that it saved time. Ratings using the disease incidence scale required only 1 to 2 min per tree, whereas direct counts required 20 to $30 \mathrm{~min}$ per tree.

Under field conditions, susceptibility to anthracnose differed greatly among cultivars, orchards, and years. The ranking of cultivars, however, did not change mark- edly with location or year, suggesting a dominant effect of genotype over the environment (weather, pathogen population, level of disease). The main exception was the Venta del Llano orchard in 2006-2007, where the low level of disease did not permit a separation of many cultivars because there were few or no affected fruit on the trees.

A major limitation for assessing cultivar susceptibility was the different ripeness times, as the susceptibility of fruit to anthracnose increases with ripeness $(18,21)$. To minimize this effect of ripeness, the date of assessment was varied with the cultivar, and disease was assessed when most fruit of each cultivar had become black, i.e., had a value of 4 on the olive ripening scale (27). Besides cultivar mis-
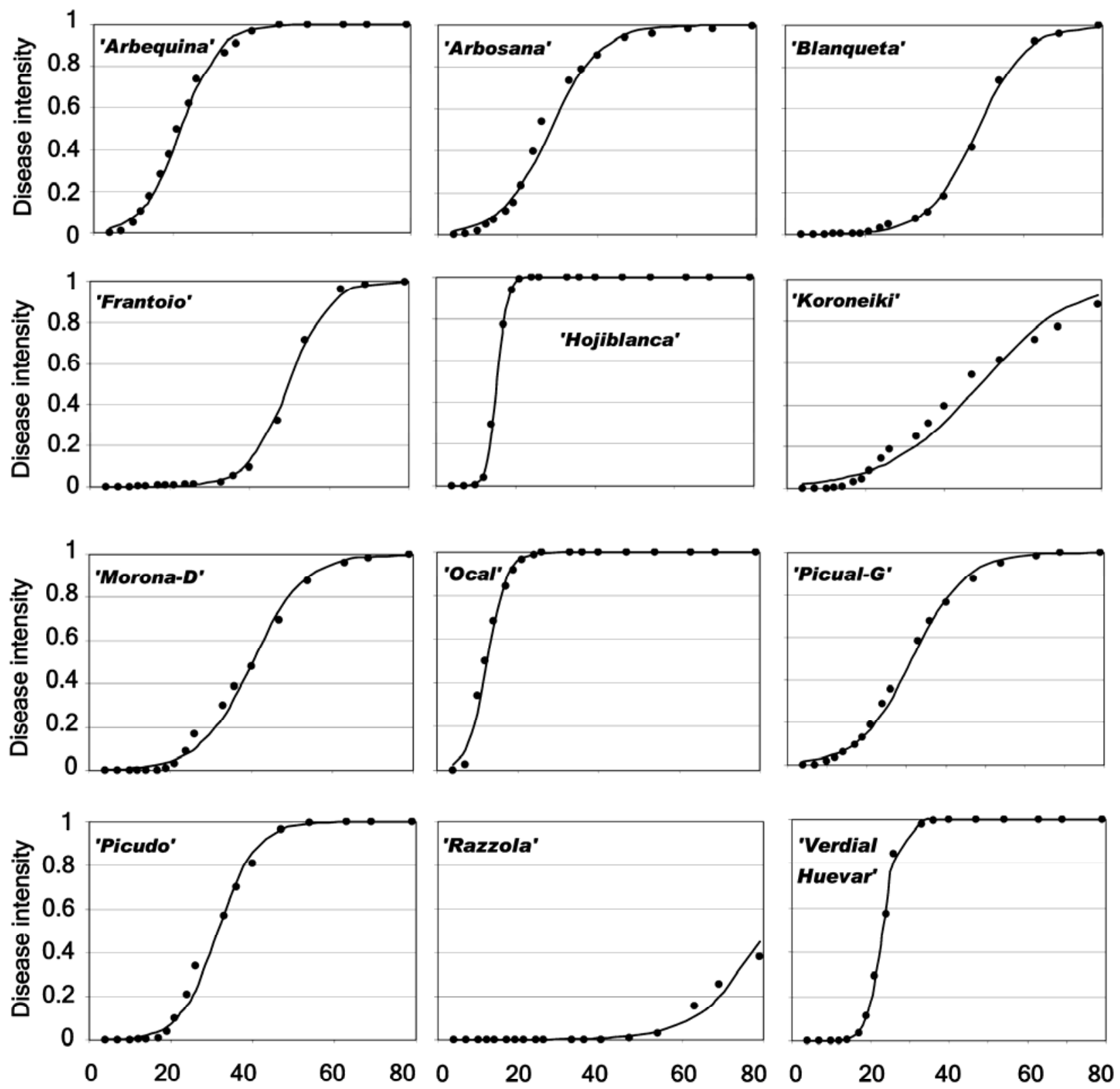

Time after inoculation (days)

Fig. 4. Disease progress in detached olive fruit of 12 cultivars inoculated with Colletotrichum acutatum. 
identification, the lack of a uniform time for disease assessment related to olive maturation may be the main cause for discrepancies among published data on cultivar susceptibility (21). Information on field conditions is limited. For example, the olive database contains data for only 53 cultivars, which are classified by their susceptibility to anthracnose as low (seven cultivars), medium (15 cultivars), and high showing some discrepancies (3). Our field assessments agree with previous observations for susceptible cultivars Arbequina, Blanqueta, Hojiblanca, Manzanilla de Sevilla, Morrut, Ocal, and Picudo, and for the resistant or moderately resistant cultivars Empeltre, Leccino, and Picual $(1,3,8,21,27,30)$. Cultivar Frantoio had low susceptibility in our assessments, which agrees with some other observations $(3,19)$, but it was considered susceptible in Argentina (8), possibly due to a misidentification of the cultivar (1). Our results are also the first report of anthracnose susceptibility under field conditions for cultivars cultivar susceptibility to anthracnose under (29 cultivars), as well as two cultivars

Arbosana, Cornicabra, Koroneiki, Lechín de Sevilla, Morona, Pajarero, Razzola, Verdial de Huévar, and Villalonga.

Other fungal fruit-rot diseases caused by species of Alternaria, Botryosphaeria, Fusarium, and Phlyctema occurred in some cultivars during our assessment of anthracnose incidence. The incidence of these diseases was low, however, and therefore did not prevent us from assessing anthracnose incidence, although the time of assessment was longer in trees affected by both anthracnose and some of these diseases. The only exception was cv. Blanqueta, which was severely affected by Phlyctema vagabunda in some orchards and years. Because symptoms caused by this fungus can be confused with anthracnose, trees severely affected by $P$. vagabunda were excluded from this study.

Leaf wilt and branch dieback are important symptoms associated with olive anthracnose (2,23). In some countries, such as Greece, Italy, and Portugal, these symptoms have been considered as a primary anthracnose syndrome caused by a direct attack of the pathogen on leaves and

Table 4. Correlation between average of anthracnose incidence for 12 olive cultivars in three experimental orchards and disease severity variables in detached olive fruit of the same cultivars artificially inoculated with Colletotrichum acutatum

\begin{tabular}{lccccc}
\hline & \multicolumn{2}{c}{ All cultivars } & & \multicolumn{2}{c}{ Without Morona and Picudo } \\
\cline { 2 - 3 } \cline { 5 - 6 } Disease variable $^{\mathbf{y}}$ & \multicolumn{1}{c}{$\boldsymbol{r}^{\mathbf{z}}$} & $\boldsymbol{P}^{\mathbf{z}}$ & & $\boldsymbol{r}^{\mathbf{z}}$ & $\boldsymbol{P}^{\mathbf{z}}$ \\
\hline SAUDPC & 0.6633 & 0.0187 & & 0.8103 & 0.0045 \\
ET $_{50}$ & -0.6519 & 0.0216 & & -0.7827 & 0.0074 \\
MDPR & 0.5309 & 0.0758 & & 0.8053 & 0.0049 \\
DSI & 0.6021 & 0.0383 & & 0.9046 & 0.0003 \\
ANCOVA & 0.5662 & 0.0549 & & 0.8833 & 0.0007 \\
\hline
\end{tabular}

y Parameters used to characterize disease intensity on detached olive fruit artificially inoculated with C. acutatum: standardized area under disease progress curve (SAUDPC), estimated time to reach $50 \%$ of disease intensity index ( $\mathrm{ET}_{50}$ ), maximum disease progress rate (MDPR), disease susceptibility index $\left(\mathrm{DSI}=\mathrm{MDPR} / \mathrm{ET}_{50}\right.$ ), and mean of disease intensity index estimated by analysis of covariance (ANCOVA).

${ }^{\mathrm{z}}$ Correlation coefficient $(r)$ and probability value ( $P$ value) using the Pearson's correlation test.

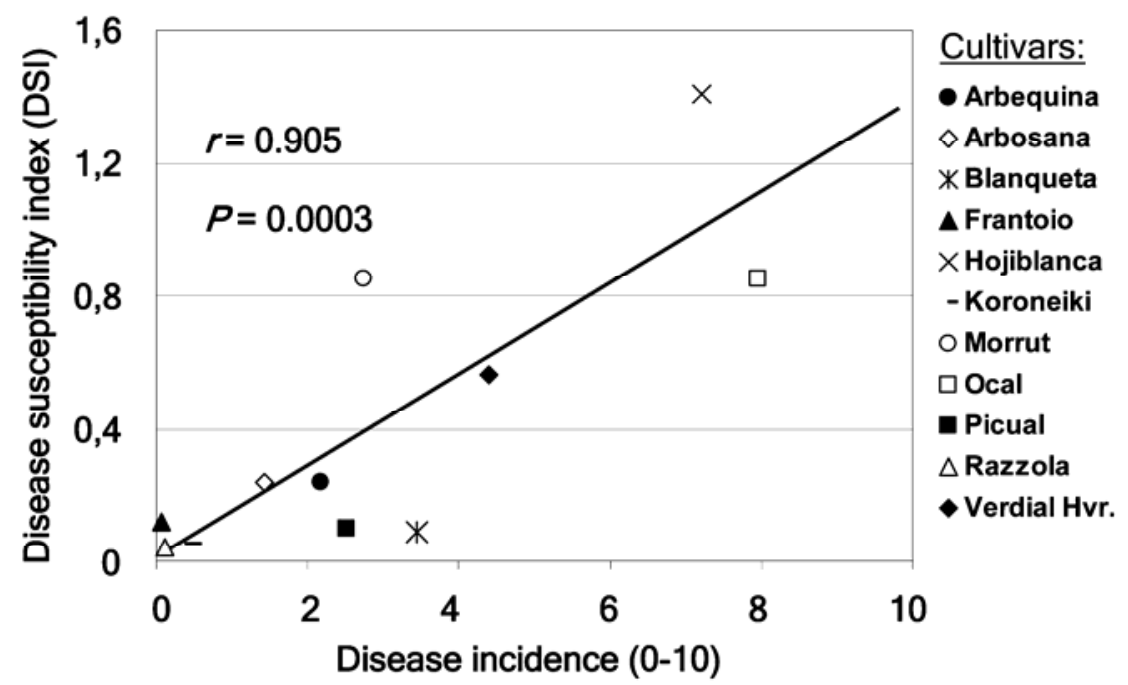

Fig. 5. Linear correlation between average anthracnose incidence in 10 olive cultivars grown in three experimental orchards and disease susceptibility index (DSI) in inoculated fruit. Disease incidence in the orchard was estimated using the rating scale 0 to 10 . DSI for artificially inoculated fruit was calculated from the logistic curve of disease intensity index over time. branches (13,33). In Spain, however, branch dieback has been considered a secondary syndrome resulting from phytotoxins produced in affected fruit (23). In this study, the pathogen was isolated from affected leaves, shoots, and branches of all sampled cultivars, but the recovery of $\mathrm{Col}$ letotrichum was low $(<3 \%)$, supporting the phytotoxin hypothesis. The results of these studies also demonstrate that, at least on susceptible cultivars, the damage caused by anthracnose on branches should be considered an important aspect of the disease. In Spain, branch dieback has been traditionally ignored, and reductions in fruit yield and oil quality were considered the only harmful effects of olive anthracnose $(8,11,18)$.

Artificial inoculation of detached fruit has been used to evaluate cultivar susceptibility to anthracnose $(12,18)$, but discrepancies exist among results from different studies and there was no relationship between artificial inoculations and field observations for some cultivars (2). To clarify these disagreements, 11 selected cultivars were assessed for their susceptibility to fruit rot using an inoculation method that considered major factors affecting disease severity under controlled conditions (21). Although the progress of disease intensity over time followed a logistic curve for all cultivars, the curves differed substantially among cultivars, and these differences depended on the variable measured: incubation period, AUDPC, $\mathrm{ET}_{50}, \mathrm{MDPR}$, and DSI. The best linear correlations between disease measured after artificial inoculation and disease incidence in the field were obtained with DSI. However, two cultivars (Morona and Picudo) showed great discrepancies and had to be eliminated from the correlation analysis. In the case of Morona, there was a misidentification of cultivar. Cultivar Picudo was very susceptible in the field but only moderately susceptible in artificial inoculations. In this case, the difference was probably due to the use of unripe fruit in the laboratory assay; although the fruit color (greenyellow) indicated ripening stage 1 , the true ripening stage (based on maturity of internal tissues) was probably lower. This was suspected because many inoculated fruit remained green-yellow at the end of the experiment, 84 days after inoculation, when most fruit of the other cultivars had become violet or black (ripening stages 3 or 4). Differences between internal and external fruit ripening stages have been reported for other late-maturing cultivars (1).

Artificial inoculations confirmed orchard observations and were consistent with the published results for most cultivars $(3,20)$. However, there were some discrepancies with respect to the reaction of some cultivars under controlled conditions. Mateo-Sagasta (18), who inoculated 
nonwounded detached fruit of 26 Spanish cultivars, found that cv. Picual was immune, Verdial de Huévar was less susceptible, and Hojiblanca and Lechín de Sevilla were moderately resistant. These cultivars were more susceptible in our study and in other studies $(2,20,27)$ than in MateoSagasta (18), perhaps because the latter study used olive fruit that were less ripe. The increase in susceptibility of fruit with maturity (21) was confirmed by our results for cv. Picual, in which mature black fruit (Picual-V) were highly susceptible and green fruit (Picual-G) were moderately resistant. The greater susceptibility of mature fruit may be related to the loss of one or several host resistance mechanisms that are present in immature fruit (26). Although these resistance mechanisms have not been studied for olive anthracnose, higher concentrations of phenolic compounds in immature than in mature olive fruits may account for the resistance of immature fruit to several olive pests and diseases (28).

Other discrepancies between our results and those published by other researchers using artificial inoculation concern cultivars Frantoio and Leccino, which have been reported to be susceptible under artificial inoculation (15), but were resistant in the current study. This difference could once again be related to the ripeness of the inoculated fruit, because our results and field observations $(1,3)$ concur on the resistance of both cultivars to anthracnose. Differences in virulence of pathogen populations also could explain some discrepancies for cultivar reaction in different places, but variation in virulence has not been studied.

Benlloch (4) and de Andrés (8) indicated that late-maturing cultivars were more affected by anthracnose than the earliermaturing ones. Our study did not demonstrate differences in susceptibility of cultivars associated with the time of ripeness because we found high susceptibility to anthracnose in early-, medium-, and latematuring cultivars. The higher incidence of anthracnose in late-ripening cultivars indicated above may be related with the excessively late harvest of these cultivars, when their fruit become black at the end of winter. In this case, cultivars that ripen early may escape from anthracnose because they are usually harvested at the end of autumn (4). However, if harvest is made before the fruit become black, as is being done at present, cultivars that ripen more slowly can be used as an avoidance strategy to reduce anthracnose epidemics, which are favored by wet and warm weather in autumn, so the planting of late-maturing cultivars has been recommended as a control practice $(5,21)$.

Based on field observations and laboratory data on susceptibility to anthracnose, cultivars were classified into three categories: highly susceptible, moderately sus- ceptible, and resistant. Because cultivar reactions varied continuously from highly susceptible to highly resistant, significant differences were found in susceptibility among cultivars within each category. Still, the simplified classification, with only three categories, will be valuable if included in a database where it can be compared with other published research.

Assessments of artificial inoculations of detached fruit complement field assessments to characterize anthracnose susceptibility in olive cultivars. At present, the rating scale and artificial inoculations are being used to assess the entire OGWB and other cultivar trials in southern Spain. These assessment methods could also be used to characterize anthracnose susceptibility of other olive cultivars and genotypes in different collections and breeding programs in the world $(3,27)$.

The use of less susceptible or resistant cultivars is the best way to control many plant diseases. Although this control method has not been considered as a priority for olive anthracnose, it will become more important for newly established plantations with a high density of trees or for hedgerow plantations. These new plantations are more vulnerable to anthracnose epidemics because the high density of trees favors pathogen dispersal and environmental conditions for infection (31). The methods described in this paper will help researchers screen olive cultivars and genotypes for anthracnose resistance.

\section{ACKNOWLEDGMENTS}

This research was funded by the Spanish Ministry of Education and Science (project AGL20047495). Thanks are due to the Andalusian Institute for Research and Formation in Agriculture and Fishery (IFAPA) for the use of experimental orchards. We are especially grateful to J. M. Caballero and C. del Río, who are in charge of the OWGB and the experimental orchards. We thank F. Luque and M. Navas for their skillful technical assistance in the laboratory and B. Jiménez, F. Ruiz, R. Acosta, and F. Cera for their expert assistance in the field work. We also thank W. J. Kaiser, B. Jaffee, and L. Rallo for critical review of the manuscript.

\section{LITERATURE CITED}

1. Barranco, D., Cimato, A., Fiorino, P., Rallo, L., Touzani, A., Castañeda, C., Serafini, E., and Trujillo, I. 2000. World catalogue of olive varieties. International Olive Oil Council \& Mundi-Prensa, Madrid, Spain

2. Barranco, D., Fernández-Escobar, R., and Rallo, L., eds. 2008. El cultivo de olivo. Junta de Andalucía \& Mundi-Prensa, Madrid, Spain.

3. Bartolini, G., and Cerreti, S. 2008. Olive germplasm (Olea europaea L.). Online publication. http://www.oleadb.it.

4. Benlloch, M. 1942. Observaciones sobre algunas enfermedades del olivo. Bol. Patol. Veg. Entomol. Agríc. 11:1-12

5. Bompeix, G., Julio, E. V. R., and Phillips, D. H. 1988. Glomerella cingulata (Stoneman) Spaulding et v. Schrenk. Pages 373-376 in: Manual de enfermedades de las plantas. I. M. Smith, J. Dunez, R. A. Lelliot, D. H. Phillips, and S. A. Archer, eds. Mundi-Prensa, Madrid, Spain.

6. Caballero, J. M., del Río, C., Barranco, D., and Trujillo, I. 2006. The olive world germplasm bank of Córdoba, Spain. Olea 25:14-19.

7. Civantos, M. 1999. Control de plagas y enfermedades del olivar. Consejo Oleícola Internacional, Madrid, Spain.

8. de Andrés, F. 1991. Enfermedades y plagas del Olivo. Riquelme y Vargas Ediciones S.L., Jaén, Spain.

9. del Moral, J., Mazón, J. J., and Santiago, R. 1986. Phlyctaena vagabunda Desm. von Arx y Fusarium moniliforme Sheldon, nuevos patógenos de la aceituna en España. Bol. San. Veg. Plagas 12:9-17.

10. FAO. 2008. The FAO Statistical Database (FAOSTAT): Food and Agriculture Organization of the United Nations. Online publication. http://faostat.fao.org.

11. García-Figueres, F. 1998. Micosis de las aceitunas y su incidencia en la calidad del aceite. Phytoma España 102:171-175.

12. García-Figueres, F., Pedret, E., Marco, V., and Duatis, J. J. 1997. Sensibilidad de diversas variedades de olivo al hongo Colletotrichum gloeosporioides. Fruticult. Prof. 88:60-63.

13. Graniti, A., Frisullo, S., Pennisi, A. M., and Magnano di San Lio, G. 1993. Infections of Glomerella cingulata on olive in Italy. EPPO Bull. 23:457-465.

14. Little, T. M., and Hills, F. J. 1975. Statistical methods in agricultural research. University of California, Davis.

15. Loprieno, N., and Tenerini, I. 1960. Studies on Gloeosporium olivarum, the cause of 'leprosy' of olive. Phytopathol. Z. 39:262-290.

16. M.A.P.A. 2006. Encuesta sobre superficie y rendimiento de cultivos. Ministerio de Agricultura, Pesca y Alimentación, Madrid, Spain.

17. Madden, L. V., Hughes, G., and van den Bosch, F. 2007. The Study of Plant Disease Epidemics. American Phytopathological Society, St. Paul, MN.

18. Mateo-Sagasta, E. 1968. Estudios básicos sobre Gloeosporium olivarum Alm. (Deuteromiceto Melanconial). Bol. Patol. Veg. Entomol. Agríc. 30:31-135.

19. Montironi, R. A. 1956. Olivo. Frantoio variedad resistente a la Antracnosis. Pulverizaciones recomendables en montes de olivo. Idia 106:176-177.

20. Moral, J., Ávila, A., López-Doncel, L. M., Alsalimiya, M., Oliveira, R., Gutiérrez, F., Navarro, N., Bouhmidi, K., Benali, A., Roca, L., and Trapero, A. 2005. Resistencia a los Repilos de distintas variedades de olivo. Vida Rural 208:34-40.

21. Moral, J., Bouhmidi, K., and Trapero, A. 2008. Influence of fruit maturity, cultivar susceptibilitity, and inoculation method on infection of olive fruit by Colletotrichum acutatum. Plant Dis. 92:1421-1426.

22. Moral, J., De la Rosa, R., León, L., Barranco, D., Michailides, T. J., and Trapero, A. 2008 High susceptibility of the olive cultivar FS- 17 to Alternaria alternata in southern Spain. Plant Dis. $92: 1252$

23. Moral, J., Oliveira, R., and Trapero, A. 2009. Elucidation of the disease cycle of olive anthracnose caused by Colletotrichum acutatum. Phytopathology 99:548-556

24. Moral, J., and Trapero, A. 2008. Evaluación de la susceptibilidad de cultivares de olivo a la Antracnosis causada por Colletotrichum spp. Page 94 in: Anonymous. Resúmenes de las comunicaciones del XIV Congreso de la Sociedad Española de Fitopatología. Sociedad Española de Fitopatología (SEF) \& Coselleria do Medio Rural, Xunta de Galicia, Lugo, Spain.

25. Oliveira, R. 2003. Etiología y control químico de la Aceituna Jabonosa causada por Colletotrichum spp. Ph.D. thesis. Universidad de Córdoba, Córdoba, Spain.

26. Prusky, D. 1996. Pathogen quiescence in postharvest diseases. Annu. Rev. Phytopathol. 34:413-434. 
27. Rallo, L., Barranco, D., Caballero, J. M., del Río, C., Martín, A., Tous, J., and Trujillo, I., eds. 2005. Variedades de Olivo en España. Junta de Andalucía, M.A.P.A. \& MundiPrensa, Madrid, Spain.

28. Ryan, D., and Robards, K. 1998. Phenolic compounds in olives. Analyst 123:31-44.

29. Talhinhas, P., Sreenivasaprasad, S., NevesMartins, J., and Oliveira, H. 2005. Molecular and phenotypic analyses reveal association of diverse Colletotrichum acutatum groups and a low level of $C$. gloeosporioides with olive anthracnose. Appl. Environ. Microbiol. 71:29872998.

30. Tous, J., and Romero, A. 1993. Variedades del olivo. Fundación "La Caixa", Barcelona, Spain.

31. Trapero, A. 2007. Enfermedades del olivar y densidad de plantación. Mercacei 51:210-212.

32. Trapero, A., López-Doncel, L. M., and Viruega, J. R. 1998. Los "Repilos" del olivo: Etiología, epidemiología y estrategias de control. Phytoma España 102:154-158.

33. Zachos, D. G., and Makris, S. A. 1963. Studies on Gloeosporium olivarum in Greece II Symptoms of the disease. Ann. Inst. Phytopathol. Benaki 5:128-130. 